\title{
VAGARIES OF LOCAL MORTALITY RATES UNDER THE 1953-54 RULES FOR TRANSFER OF DEATHS
}

\author{
BY \\ DAVID HEWITT \\ Social Medicine Unit, University of Oxford
}

An interesting and valuable feature of the Statistical Review published annually by the Registrar-General is the Table which compares the mortality of each local government area in England and Wales. Great care has been taken to present these comparisons in a way which discounts the effect of local variations in the sex and age structure of the population. Since 1934 the method of standardization has been to multiply each crude death rate by an "area comparability factor", computed from census data, and then to divide the product by the crude death rate for England and Wales as a whole. The resulting figure is termed the "ratio of local adjusted death rate to the national rate" (hereafter referred to as the "local ratio"). In the Text Volume of his 1951 Review the Registrar-General states that this procedure "provides a valid basis of comparison between areas of mortality rates relating to deaths from all causes within the same year, except for areas whose area comparability factor may be unreliable for certain years" (Registrar-General, 1954). The 1953 Text Volume contains a similar statement, but adds that the method does not "take account of the influence of certain types of institution, e.g. chronic sick hospitals, on the death rate of the area" (RegistrarGeneral, 1956). The need for this additional qualification arose from a change in registration practice ordered in 1952.

The new rules of procedure were set out in a memorandum circulated by the General Register Office in October, 1952, and reproduced in the Text Volume of the 1953 Review. The main provisions of the Memorandum was that persons dying on or after January 1, 1953*, in a mental hospital, mental deficiency institution, or hospital for the chronic sick were to be regarded as residents of the area in which they died, whether or not they had been living

* But it was clear from the statistics that this rule must have come into force in some areas in 1952. The most recent volume of Tables, that for 1955, states that the change made in 1952 related to "persons dying in accommodation provided under Parts III and IV of the National Assistance Act, 1948". in the same area before admission to the hospital or institution. This change was immediately unpopular with the Medical Officers of Health for some of the areas in which large hospitals were situated, and as a result of their representations a minor change was announced in a Circular of January, 1954 (General Register Office, 1954). Without abandoning the view that inmates of long-stay institutions ought to be regarded as normally resident in the area of the institution, this Circular provided that certain chronic hospitals which admitted a considerable proportion of acute cases should be treated as general hospitals, i.e. deaths occurring in them would be allocated, as formerly, to the areas from which patients had been admitted. To qualify for this treatment, "the ratio of the number of deaths and discharges to the average daily bed occupation should be two or more in each of the two most recent years for which figures are available".

The disturbing effect on local mortality figures of these successive changes may be illustrated by citing what is probably the most extreme case. The Municipal Borough of Eye in East Suffolk has a population of approximately 1,600 and since the normal mortality of this population is below the national level it generally has less than twenty deaths in a year. However, the area contains a sizeable chronic hospital, and in 1953 the borough was assigned 138 deaths giving a local ratio of no less than 5.08. $\dagger$ Since the hospital satisfied the 1954 criterion for treatment as a general hospital the deaths attributed to Eye fell back in the following year from 138 to nineteen. This latter change resulted from the fact that, of the 122 occupied beds in the hospital, an average of four were in use for maternity cases and these contributed 149 to the total of 378 discharges and deaths during the year (Ministry of Health, 1956). Had the chronic part of the hospital been considered as a separate institution (the course recommended where possible by

† By a very natural slip the death rate for this area in 1953 was published as 8.5 per thousand instead of 85.2 , and the local ratio as 0.51 instead of 5.08 . 
the 1952 Memorandum), the borough might have had a local ratio in 1954 as high as the absurd figure for 1953. There are a number of other areas (e.g. Totnes U.D., Lichfield M.B.) in which reversion to normal ratios was brought by the presence of a small maternity unit in a hospital mainly devoted to the chronic sick.

In areas such as Eye M.B. the local ratio may be expected to remain at a normal level from 1954 onwards, but a series of abrupt upward and downward changes could easily occur where there is a large hospital with an annual number of discharges close to twice the average bed occupation. This possibility is illustrated by Maidenhead M.B. (census population 27,125) where there is a hospital for the chronic sick disproportionately large in comparison with the size of the town. As the average daily bed occupation at this hospital during 1953 was 166 , it required 332 deaths or discharges to remove it from the chronic category and there were in fact 333. The local ratio accordingly fell from 1.33 in 1953 to 0.81 in 1954 . This case brings to light a remarkable paradox resulting from the current registration procedure: that a small but genuine increase in the number of deaths in a hospital for the chronic sick may produce a large but artificial decrease in the official death-rate of the surrounding area.

Of greater importance than the areas in which a normal situation was restored, by accident or design, in 1954 are the more numerous areas where an artificial inflation of the local ratio threatens to remain as long as the current regulations stay in force. These are not easy to enumerate in full, because the effect in populous areas naturally tends to be small and because one cannot always exclude the possibility that a genuine increase in local mortality coincided with the introduction of the new regulations. Moreover, it would be misleading to suggest that any list of areas where the local ratio has risen could give a full account of the effect of these regulations. For, if it is agreed that the new regulations give rise to spurious increases in the mortality of areas which "import" chronic or mental invalids, then it must also be the case that there are spurious (albeit smaller) decreases in all other areas, except those which (if they exist) cater exactly for the chronic and mental bed requirements of their own residents. However, it is comparatively easy to identify the most seriously affected areas, and a list of 106 of these is given in the Appendix to this paper. This list is restricted to areas which satisfy the following three requirements: they contain a number of chronic, mental, or mental deficiency beds which is large relative to the population; local ratios suggest an increase in mortality since the introduction of the new rules; and deaths attributed to the area have increased by a number which is unlikely to be due to chance. The test for meeting the third of these requirements was as follows: if $A$ represents the number of deaths in the 2 years preceding the change in regulations, and $B$ represents the number in the 2 years following, then the quantity $\frac{(B-A)^{2}}{A+B}$ should be greater than $9 \cdot 55$.

Since the only cases to be considered are those in which $B$ exceeds $A$, this is equivalent to a $\chi^{2}$ test at the 1 in 1,000 level. As the null hypothesis takes no account of the contemporary decrease in deaths in the country as a whole, and as there are less than 1,500 areas altogether, this requirement is probably adequate to exclude trivial or illusory cases. The use of pairs of years in the comparison should help to reduce the influence of epidemic fluctuations, but it is possible that an area which escaped lightly in the 1951 outbreak of influenza and then suffered badly in 1953 might be wrongly included in the list. The total of 106 areas does not include those in which there was a reversion to normal in 1954, but an additional list is given in the Appendix of 23 such areas in which the transitory increase, as judged from a comparison of two single years, was as significant as the more permanent increase in the 106 areas.

The areas in the main list range in population from 1,713 (Woodstock M.B.) to 333,328 (Wandsworth Met. B.). As might be expected, they include a considerable number of small population units, but the average population is 86 per cent. as great as the average for all local government areas in England and Wales. Their aggregate population is nearly $2,750,000$, and the crude death rate of this aggregate has risen from about 10 per cent. below the national level to about 30 per cent. above it. In twelve cases the local ratio has been more than doubled. That this is not an exhaustive list is illustrated by the failure of Ilford M.B. to pass the three requirements listed above, although, from local knowledge, the Medical Officer of Health for this large town has been able to show that it has suffered an inportant artificial increase in mortality under the current rules (Gordon, 1956).

Although the list contains only about one in fifteen of local government areas in the country as a whole, it includes eight of the fifty areas whose boundaries touch the edge of the Greater London Conurbation. This no doubt reflects the position of the central London area as the greatest "exporting" area of chronic and mental patients. In ten Metropolitan Boroughs of the County of London, the 
local ratios for 1953 and for 1954 were both lower than for any of the preceding 5 years. But the new regulations show their effect on this large "exporting" area, not so much by the few instances of a dramatic fall in local ratio as by the disturbance of the established general pattern of local mortality. Attention has already been drawn to a sudden change in the apparent distribution within London of mortality from respiratory disease (Hewitt, 1956). The Table shows what has happened in this region to the mortality from all causes, setting out the correlations for each year from 1948-54 between the local ratios of the 28 Metropolitan Boroughs and two traditional indices of adverse living conditions taken from the County Census Report (General Register Office, 1953). With the introduction of the new regulations, these correlations have fallen precipitately: in the case of density per room to about one-sixth and in the case of low economic status to about one-third of the former level. It is true that the correlations showed a fall in 1952, (which, by virtue of the December fog disaster, was an exceptional year), but there can be little doubt that the unprecedentedly low correlation in 1953, persisting in 1954, is due to artificial causes. It must be concluded that the official death rates of the Metropolitan Boroughs have lost the value which they formerly had both for administrators and for research workers.

TABLE

METROPOLITAN BOROUGHS OF LONDON CORRELATION BETWEEN TWO INDICES OF ADVERSE LIVING CONDITIONS AND THE RATIO OF LOCAL ADJUSTED TO NATIONAL DEATH RATE

\begin{tabular}{|c|c|c|}
\hline \multirow[b]{2}{*}{ Year } & \multicolumn{2}{|c|}{ Index } \\
\hline & $\begin{array}{c}\text { Ratio of Persons } \\
\text { to Rooms }\end{array}$ & $\begin{array}{c}\text { Per cent. of } \\
\text { Occupied Males } \\
\text { in Social Classes } \\
\text { IV and V }\end{array}$ \\
\hline $\begin{array}{l}1948 \\
1949 \\
1950 \\
1951 \\
1952\end{array}$ & $\begin{array}{r}+.844 \\
+.854 \\
+.737 \\
+.772 \\
t \cdot 549\end{array}$ & $\begin{array}{l}+.840 \\
+.887 \\
+.838 \\
+.755 \\
t .622\end{array}$ \\
\hline Average $1948-52$ & $t \cdot 751$ & $t \cdot 788$ \\
\hline $\begin{array}{l}1953 \\
1954 \\
\end{array}$ & $\begin{array}{l}+\cdot 152 \\
t \cdot 111 \\
\end{array}$ & $\begin{array}{l}+\cdot 241 \\
t \cdot 293 \\
\end{array}$ \\
\hline Average $1953-54$ & $t \cdot 132$ & $t \cdot 267$ \\
\hline
\end{tabular}

It is fortunate that the local ratios for the County Boroughs which, together with those for the Metropolitan Boroughs, customarily receive the most attention, have been less severely affected. This is probably because most County Boroughs come tolerably near to balancing their own requirements for mental and chronic beds. (Among the possible exceptions are Burton on Trent, East Ham, Oldham, Preston, Smethwick, Wakefield, and West Ham.)

\section{Discussion}

These unfortunate consequences of the new regulations probably could not have been foreseen in 1952, and might be acceptable even now if they were balanced by some solid advantage. But any such advantage is hard to detect. The object of transfer procedure, as set out concisely in the 1952 Memorandum, is to ensure "that vital events should, whenever possible, be assigned to the area of the population at risk". There is no doubt about the application of this principle when a patient is removed from his home to another area during an acute and fatal illness. The application is certainly less clear in the case of a patient who has spent months or possibly years in an institution and may finally die from a disease which could not possibly have been diagnosed at the time of his first admission to hospital. But the principle is the same. Persons admitted to mental hospitals or hospitals for the chronic sick are known to have death-rates several times higher than those of the general population. Moreover, the bulk of deaths in these institutions, as outside them, are due to conditions which originate in the course of decades rather than in months or years. The average duration of stay in a mental hospital for patients discharged or dying during 1953 was less than 2 years, and in chronic hospitals only 6 months (Ministry of Health, 1956). Most of the patients who have spent even four times this average period in hospital will have lived three-quarters or more of their lives outside hospital. Even the death of a child with congenital mental defect who may have spent almost all his life in an institution ought surely (like the stillbirth of a malformed infant) to be assigned to the area of his mother's usual residence. In short, length of residence in a hospital or institution does not of itself justify any registration procedure different from that which is still admitted to be appropriate in the case of a general hospital.

It may be, however, that the decision to introduce the new regulations was determined in part by considerations of convenience or economy. The saving of effort must, however, be small in relation to that still required to effect the transfer of deaths occurring in general hospitals. The extra costs which would be incurred by re-introducing the old scheme can only be estimated by the authorities, but one may guess that it could easily be covered, for example, by a small increase in the charges made for searches and certificates. In any case, the present compromise between a thoroughgoing transfer 
system and the primitive system by which all deaths are assigned to the area of occurrence can hardly be held to yield an adequate return for the labour involved. As Gordon (1956) observed, "It may well be asked why the Registrar-General goes to the trouble of providing each district with a comparability factor to standardize its death-rate for age and sex when large errors resulting from official manipulation of hospital deaths may completely vitiate the result".

Fortunately the Circular letter to Medical Officers of Health in 1954 (General Register Office, 1954) promised that the new regulations would be reconsidered after a trial period. It is to be hoped that these regulations do not become a permanent part of our registration system.

\section{SUMMARY}

The new regulations introduced in 1953 and 1954 regarding the statistical treatment of deaths occurring in hospitals for the chronic sick, mental hospitals, and mental deficiency institutions have had a deleterious effect on local mortality figures. Upwards of a hundred areas which "import" chronic or mental invalids have experienced a significant and spurious rise in their local mortality rates, while opposite though less dramatic effects have occurred in "exporting" areas. Effects of the latter type are seen at their worst in the London area. It is suggested that a return to the rules in force before 1953 is desirable.

\section{REFERENCES}

General Register Office (1953), Census 1951. England and Wales. County Report, London. H.M.S.O., London.

General Register Office (1954). G.R.O. Circular (Medical Officer of Health) No. 2/1954 (unpublished).

Gordon, I. (1956). Med. Offr., 96, 255.

Hewitt, D. (1956). British Journal of Preventive and Social Medicine, $10,45$.

Ministry of Health (1956). "National Health Service. Hospital and Specialist Services. England and Wales. Statistics for the Year ended 31st December, 1953". H.M.S.O., London.

Registrar General for England and Wales. "Annual Statistical Review", Tables, Part I, Medical, for 1948-55 (published 1950-56) and Text Volumes for 1951 and 1953 (published 1954 and 1956).

\section{APPENDIX}

The following lists give the areas which are judged, according to the criteria stated in the text, to have suffered a spurious increase in local mortality since the introduction of the new transfer regulations. Those in List II had reverted to a normal level by 1954, those in List I had not. The figure after each

\section{List I}

Berkshire: Wallingford M.B., 166.

Cheshire: Knutsford U.D., 72*; Chester R.D., 59; Congleton R.D., 74.

Cornwall: Bodmin M.B., 165; Liskeard M.B., 77.

Derbyshire: Ashbourne U.D., 53; Bakewell U.D., 96.

Devon: St. Thomas R.D., 42; Totnes R.D., 37; Wareham M.B., 65*; Wimborne Minster U.D., 53.

Durham: Sedgefield R.D., 32; Sunderland R.D., 37.

Ely: Ely M.B., 53; Wisbech M.B., 32.

Essex: Brentwood U.D., 28; Colchester M.B., 24;

Hornchurch U.D., 32; Tendring R.D., 22*.

Gloucestershire: Gloucester R.D., 51; Thornbury R.D., 22.

Herefordshire: Hereford R.D., 45.

Hertfordshire: Ware U.D., 75*; Elstree R.D., 165; St. Albans R.D., 139; Watford R.D., 56.

Huntingdonshire: Huntingdon M.B., 98*. area indicates the percentage by which the mean of the local ratios for the pair of years following the change exceeded the mean for the pair of years preceding it (single years only for List II).

An asterisk indicates that the new rules had evidently come into operation during 1952.

Kent: Dartford M.B., 32; Faversham M.B., 69*; Sittingbourne and Milton U.D., 53; Tenterden M.B., 61; Bridge Blean R.D., 49; Eastry R.D., 39; Elham R.D., 50; Maidstone R.D., 55; West Ashford R.D., 73.

Lancashire: Billinge and Winstanley U.D., 272; Eccles M.B., 26; Lancaster M.B., 18; Prestwich M.B., 19; Rawtenstall M.B., 122; Preston R.D., 38; Warrington R.D., 57.

Lincolnshire: North Kesteven R.D., 49.

London: Wandsworth Met. B., 16.

Middlesex: Friern Barnet U.D., 55; Southall M.B., 35.

Norfolk: Downham Market U.D., 74*; Forehoe and Henstead R.D., 28; St Faith's and Aylsham R.D., 35.

Northamptonshire: Brixworth R.D., 52.

Northumberland: Gosforth U.D., 44; Morpeth M.B., 54; Castle Ward R.D., 103*.

Nottinghamshire: Bingham R.D., 43.

Oxfordshire: Woodstock M.B., 160*.

Rutland: Oakham U.D., 76. 
Shropshire: Bishop's Castle M.B., 120*; Wenlock M.B., 38; Whitchurch U.D., 44; Oswestry R.D., 44.

Somerset: Keynsham U.D., 40; Taunton R.D., 48.

Southampton; Basingstoke R.D., 98; Winchester R.D., 46.

Staffordshire: Stafford M.B., 27; Stone U.D., 128; Cheadle R.D., 41 ; Lichfield R.D., 30.

Surrey: Banstead U.D., 66; Coulsdon and Purley U.D., 35; Epsom and Ewell M.B., 68; Woking U.D., 17.

Sussex, East: Cuckfield U.D., 24; Newhaven U.D., 55; Chailey R.D., 36; Hailsham R.D., 30.

Sussex, West: Chichester, M.B. 31.

Warwickshire: Bedworth U.D., 95; Warwick R.D., 86. Isle of Wight: Newport M.B., 32.

Wiltshire: Chippenham M.B., 35; Salisbury M.B., 28 ; Warminster U.D., 56; Bradford and Melksham R.D., 39; Devizes R.D., 76.

Worcestershire: Bromsgrove U.D., 32; Upton-on-Severn R.D., 46.

Yorkshire, East Riding: Haltemprice U.D., 29; Beverley R.D., 47.

Yorkshire, West Riding: Aireborough U.D., 34; Goole M.B., 45; Hemsworth U.D., 125; Holmfirth U.D., 49; Kirkburton U.D., 85; Rothwell U.D., 46; Skipton U.D., 49; Wortley R.D., 40.

Anglesey: Valley R.D., 37.

Brecknockshire: Hay R.D., 105.

Carmarthenshire: Carmarthen M.B., 36.
Denbighshire: Denbigh M.B., 87.

Glamorgan: Penybont R.D., 40.

Monmouthshire: Caerleon U.D., 66; Abergavenny R.D., 97.

\section{List II}

Berkshire: Maidenhead M.B., 45.

Buckinghamshire: Newport Pagnell U.D., 137.

Cheshire: Nantwich U.D., 186.

Devonshire: Barnstaple M.B., 49; Honiton M.B., 241; Totnes M.B., 83.

Dorset: Dorchester M.B., 51.

Essex: Leyton M.B., 58; Maldon M.B., 75.

Lancashire: Atherton U.D., 77; Fylde R.D., 54.

Northamptonshire: Daventry M.B., 289*; Oundle U.D., 96; Kettering M.B., 30.

Southampton: Christchurch M.B., 45.

Staffordshire: Lichfield M.B., 69.

Suffolk: Eye M.B., 642.

Worcestershire: Evesham M.B., 104; Kidderminster M.B., 36.

Yorkshire, West Riding: Knaresborough U.D., 112; Pontefract M.B., 48*.

Glamorgan: Pontypridd U.D., 29.

Pembrokeshire: Haverfordwest M.B., 83. 